\title{
A study on the damage evolution of P91 steel under cyclic loading at high temperature
}

\author{
A.A. Saad ${ }^{1}$, Z. Bachok ${ }^{1}$ and W. Sun ${ }^{2}$ \\ ${ }^{1}$ School of Mechanical Engineering, Engineering Campus, Universiti Sains Malaysia, \\ 14300 Nibong Tebal, Pulau Pinang, Malaysia \\ *Email: azizsaad@usm.my \\ Phone: +6045996384; Fax:+6045941024 \\ ${ }^{2}$ Materials, Mechanics and Structures Research Division, Faculty of Engineering, \\ The University of Nottingham, NG7 2RD, UK
}

\begin{abstract}
This study aimed to investigate the effect of cyclic loading on structural integrity of a P91 specimen at high temperature. The experiments were conducted using a thermomechanical fatigue test machine at $600{ }^{\circ} \mathrm{C}$ and electron microscopy investigation. The evolution of the elastic modulus can be used as an indication of the strength degradation of the material. Scanning and transmission electron microscopy were used to investigate the microstructural variations that occurred in the specimen at different life fractions during the cyclic tests. Based on the experimental stress-strain data, variations in the Young's modulus and the area enclosed in the hysteresis loops were determined, together with the variations in other parameters throughout the test. The initiation of cracks begins in the second stage of cyclic softening. The changes of structure, on a micro-scale, do not significantly affect the strength of the specimen, as the Young's modulus values of the specimen remain approximately constant up to the end of the stage 2 cyclic softening before damage to the specimen starts to increase. The cracks cause the material to become weaker, as indicated by the decrease of the Young's modulus value. The evolution of damage was found to be significant in the final stages of softening owing to the propagation of cracks in the P91 steel affecting the integrity of the material.
\end{abstract}

Keywords: P91 steel; cyclic loading; microstructural evolution; damage.

\section{INTRODUCTION}

Martensitic steel with 9-12\% Cr, such as P91 steel, has been used in the power generation industry to improve the thermal efficiency of power plant pipes and tubes. Understanding the structural behaviour of steel under cyclic thermal-mechanical conditions has become more important as the current operation involves more cyclic operations, which has introduced the possibility of thermo-mechanical fatigue (TMF) problems. Several failures owing to TMF problems have been found in the power generation industry, such as bore cracking owing to the effects of varying steam temperatures [1, 2]. The temperature cycling causes thermal gradients between the inside and outside of the components, which can cause cyclic stress levels to be of concern particularly, between the weld and parent materials of the pipe. The stress concentration area may initiate cracks that eventually cause damage to the piping structure. Many studies on power plant materials have been focused on creep and cyclic loading conditions to simulate the behaviour of the materials at high temperature. For example, creep constitutive equations have been developed for 
different parts of the piping section in the range of 565-640 ${ }^{\circ} \mathrm{C}$ [3]. Similar studies have been carried out to develop a creep constitutive model with damage capability for a P91 steel [4]. As the creep fatigue and thermomechanical fatigue conditions attract more attention from the power plant industry, the cyclic loading behaviour model has been given more focus recently. Simple and complex power plant components under operation can be simulated based on the cyclic plasticity model $[2,5,6]$. The behaviour of P91 steels at the microstructure level under cyclic loading can also be visualised and simulated using micromechanical finite element modelling [7]. The prediction of the behaviour of the power plant materials can be further extended to predict fatigue life using various available models [8-10].

Experimental studies of cyclic loading at high temperatures exhibit certain characteristics of martensitic steels. The steel generally exhibits cyclic softening behaviour as the peak stresses decrease as the number of cycles increases $[11,12]$. The application of cyclic mechanical loading of P91 steel at high temperature causes microstructural and damage evolution throughout the material's life cycles. The microstructural evolution occurs on a subgrain scale and thus a transmission electron microscope is required to investigate this phenomenon [13]. The damage evolution can be indirectly measured based on Young's modulus values using the damage mechanics concept [14]. It is important to understand the damage evolution of the steel specimen throughout its life cycle and the experimental data assists researchers in predicting the behaviour of the steel at high temperatures using computational methods $[15,16]$. This paper presents the analysis of the structural behaviour and damage evolution of P91 steel under cyclic operation at high temperature. It also contains an investigation of the microstructural variations that occur in specimens during the cyclic tests at different life fractions using scanning and transmission electron microscopes. The relationships between the cyclic stress-strain data and the results obtained from the microstructural investigations are used to gain an understanding of the damage evolution of P91 steel under cyclic loading.

\section{EXPERIMENTAL SETUP}

\section{Testing Facilities}

An Instron $8862 \mathrm{TMF}$ testing system was used to perform the cyclic test at $600{ }^{\circ} \mathrm{C}$. The system consists of a load frame, a servo electric actuator, a power amplifier, a load cell and the control electronics. The machine is controlled by a servo electric screw-driven actuator for forces up to $100 \mathrm{kN}$. The maximum frequency is $1 \mathrm{~Hz}$ and the minimum speed is 1 micrometre/hour in a displacement controlled test. Strain is measured by high temperature extensometer with ceramic rods and a gauge length of $12.5 \mathrm{~mm}$. This extensometer can be used at temperatures up to $1200{ }^{\circ} \mathrm{C}$. The heat is supplied by highfrequency induction heating. The heat is produced by the interaction of the test specimen, which is a metal, with the magnetic field generated by the flow of alternating current in an induction coil. The coil is made of copper tubing designed to enable the temperature gradient along the gauge section to be controlled to within $\pm 10{ }^{\circ} \mathrm{C}$ of the target temperature. The induction heating enables a fast heating rate up to $50{ }^{\circ} \mathrm{C}$ per second to be achieved and a cooling rate up to $25^{\circ} \mathrm{C}$ per second is achieved with forced air. These test control capabilities are important in thermo-mechanical fatigue tests in order to achieve the required temperature cycles. 


\section{Material and Specimen Preparation}

The material used in this work was a 9\% Cr steel alloy, also known as P91 steel, machined from a steam pipe. The P91 pipe had an outer diameter of $298.5 \mathrm{~mm}$ and a wall thickness of $55 \mathrm{~mm}$. The P91 steel was austenised at $1060{ }^{\circ} \mathrm{C}$ for 45 minutes and tempered at 760 ${ }^{\circ} \mathrm{C}$ for 2 hours. The chemical compositions of the material are given in Table 1 .

Table 1. Chemical compositions for the P91 steel (wt\%).

\begin{tabular}{ccccccccccccc}
\hline & $\mathrm{Cr}$ & $\mathrm{Mo}$ & $\mathrm{C}$ & $\mathrm{Si}$ & $\mathrm{S}$ & $\mathrm{P}$ & $\mathrm{Al}$ & $\mathrm{V}$ & $\mathrm{Nb}$ & $\mathrm{N}$ & $\mathrm{W}$ & $\mathrm{B}$ \\
\hline P91 & 8.60 & 1.02 & 0.12 & 0.34 & $<0.002$ & 0.017 & 0.007 & 0.24 & 0.070 & 0.060 & 0.03 & - \\
\hline
\end{tabular}

Cylindrical, button-end, specimens (Figure 1) were machined from the P91 steel. The specimens had an overall length of $160 \mathrm{~mm}$, which is $10 \mathrm{~mm}$ longer than that suggested by the TMF machine supplier; this was more convenient for the production of a coil that gave the required temperatures within the tolerance limits. The button-end design of the specimens, as shown in Figure 1, enabled the TMF machine system to be used within the maximum load for the machine, i.e., $35 \mathrm{kN}$ during the test. The middle section of the specimen is called the gauge section and was at least $15 \mathrm{~mm}$ in order to allow the placement of the extensometer arms, which have a length of $12.5 \mathrm{~mm}$. This section was finished by fine machining and polishing to create an average roughness value of $0.8 \mu \mathrm{m}$.

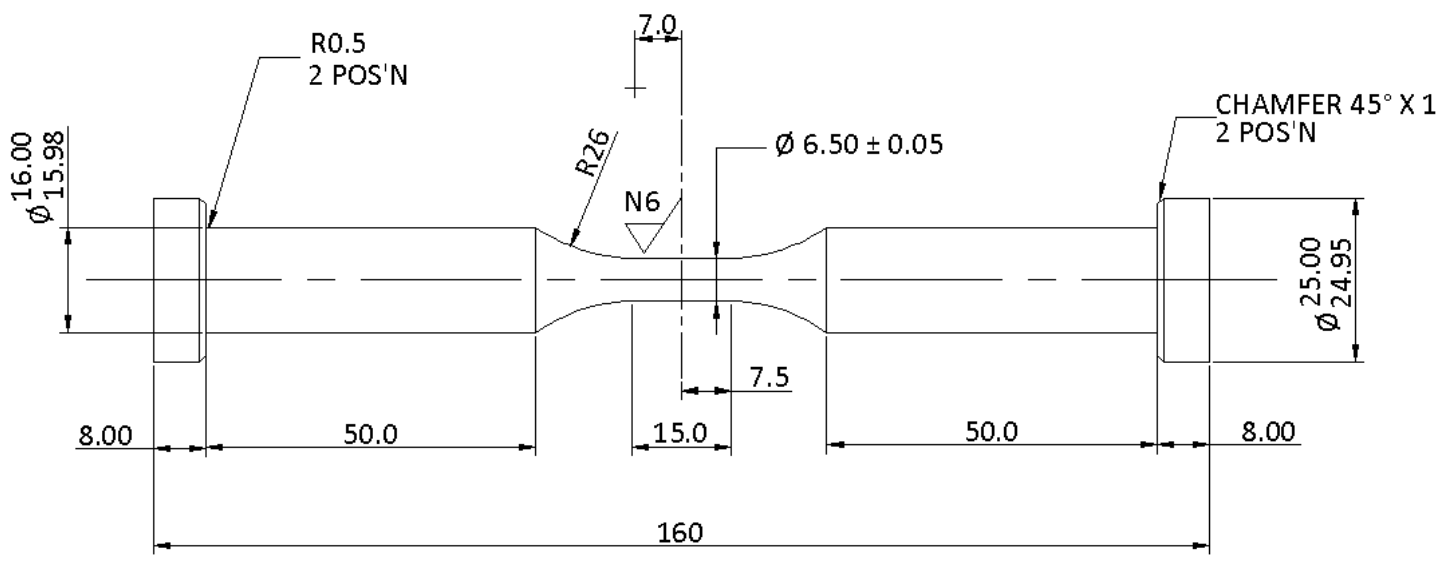

Figure 1. The solid TMF specimen used in the isothermal test.

\section{Testing Procedures - Isothermal Cyclic Plasticity Test of P91 Steel}

Strain-controlled testing was used to investigate the behaviour of P91 steel under cyclic plasticity conditions in isothermal conditions. The test loading conditions were based on the high temperature requirements of a power plant and to produce a deformation that will give plastic behaviour. The isothermal tests of P91 specimens were conducted at 600 ${ }^{\circ} \mathrm{C}$ under displacement-controlled tests with a strain amplitude of $\pm 0.5 \%$ and a strain rate of $0.1 \% / \mathrm{s}$ in fully reversed tension-compression conditions. The strain amplitude value was selected to ensure that significant plasticity would occur with this amplitude. In addition, several strain-controlled tests, with the same parameters, were repeated to investigate the microscopic evolution at a certain time frame.

Prior to starting up each test, temperature calibration of the TMF machine system was performed in order to obtain a temperature variation within the gauge length of \pm 10 ${ }^{\circ} \mathrm{C}$ of the target temperature. Once the temperature calibration and proportional, integral 
and derivative (PID) tuning procedures were completed, the tests were performed. The specimen was installed on the test rig as shown in Figure 2. The specimen was heated without applying any load for up to 5 minutes in order to stabilise the temperatures throughout the solid specimen. During that time, the mechanical strain waveform was set as required and a failure criterion, which set the condition for the machine to stop, was defined as a given percent decrease of maximum stress from a certain cycle. From the results of the first test on a $\mathrm{P} 91$ specimen at $600{ }^{\circ} \mathrm{C}$ with $\pm 0.5 \%$ strain amplitude, using a $50 \%$ stress decrease from a stabilised period, e.g. the $50^{\text {th }}$ cycle, as the failure criterion, the specimen were found to totally fracture and the extensometer fell down. This may cause damage to the extensometer if it occurs regularly. Thus, a lower percent stress decrease, i.e., 30\% stress drop from the stabilised cycle, was defined as the failure criterion for the remaining tests and the tests were found to stop without causing total fracturing of the specimen. Visible cracks were observed on all specimens' surfaces. Test data were recorded automatically using Instron TMF software.

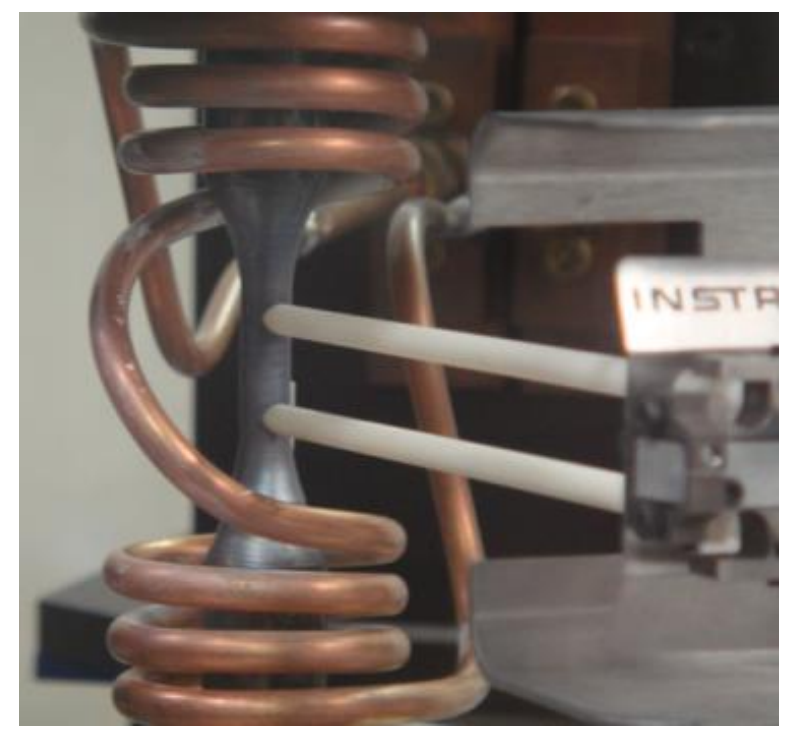

Figure 2. TMF test machine setup used for P91 specimens with induction heating coil and the extensometer.

\section{Scanning Electron Microscopy}

A Philips/FEI XL-30 scanning electron microscope (SEM) was used in this work. An accelerating voltage of $20 \mathrm{kV}$ and a working distance of $10 \mathrm{~mm}$ were set to investigate the microstructure of the P91 specimen tested at $\pm 0.5 \%$ strain amplitude. The SEM specimens were taken from the longitudinal direction of the specimen's gauge section. The samples were then mounted with conductive phenolic mounting resin. The surfaces of the samples were ground and polished by using a rotary grinding machine, with silicon carbide paper and diamond cloth, down to a $1 \mu \mathrm{m}$ finish. The samples were then further polished using colloidal silica in order to remove the residual surface damage induced by the diamond cloth polishing. Finally, acidic ferric chloride was used as the chemical etchant to reveal the microstructural features of the material.

\section{Transmission Electron Microscopy}

An investigation using a transmission electron microscope (TEM) was carried out to observe the microstructural features at higher magnifications, looking in particular for 
martensite lath structures, which cannot be clearly observed by SEM. A JEOL 2000FX transmission electron microscope at $200 \mathrm{kV}$ was used in the examination of the steel. TEM investigations require an extremely thin specimen in order to allow the electrons to pass through it and to create the TEM images. The thin foil specimen used in this work was taken from the P91 specimen, perpendicular to the loading axis. A $2 \mathrm{~mm}$ thick slice was cut from the gauge section and then ground down to approximately $100 \mu \mathrm{m}$ thick using silicon carbide paper. Then, the thin foil was punched into a $3 \mathrm{~mm}$ diameter disc using a mechanical puncher. The disc was further polished down to a thickness of approximately $50 \mu \mathrm{m}$. Finally, the disc was thinned using dual jet electropolishing at -10 ${ }^{\circ} \mathrm{C}$ in an electrolyte made up of $10 \%$ perchloric acid and $90 \%$ ethanol.

\section{RESULTS AND DISCUSSION}

The specimens tested in this study exhibited a cyclic softening behaviour, which consists of three stages, as can be seen from the evolution of the peak stress shown in Figure 3. In the initial stage, the peak stress level decreases rapidly with cycle number $\left(\mathrm{N}_{\text {sta }}\right)$. The rate of decrease becomes slower before reaching a constant value during the second stage $\left(\mathrm{N}_{\text {tan }}\right)$. The constant decrease may be related to the internal microstructure changing as the coarsening of subgrains is observed and the dislocation density also decreases owing to cyclic deformation, as reported by Fournier, Sauzay [13]. The second stage occupies the largest proportion of the cycles. Finally, the rate of reduction of the stress level increases rapidly leading to failure $\left(\mathrm{N}_{\mathrm{f}}\right)$. The $\mathrm{N}_{\mathrm{sta}}$ and $\mathrm{N}_{\mathrm{tan}}$ correspond to the beginning of the constant rate evolution of the peak stress level and the beginning of the stress drop in the third stage, respectively, as suggested by Constantinescu, Charkaluk [17]. The number of cycles to failure, $\mathrm{N}_{\mathrm{f}}$, is defined, according to the BS7270:2006 standard, as the cycle number at which the maximum stress has decreased by a prescribed percentage from that predicted by extrapolation of the second stage stabilisation curve. In the standard, a 10\% drop $\left(\mathrm{N}_{\mathrm{f} 10}\right)$ is suggested as a possible failure criterion [18]. However, other percentages could be used. Finally, $\mathrm{N}_{\text {fin }}$ represents the final number of cycles applied in the cyclic test, as recorded by the TMF machine, before it stops as a result of the machine setting. This avoids the total fracture of the specimen, which could damage the machine.

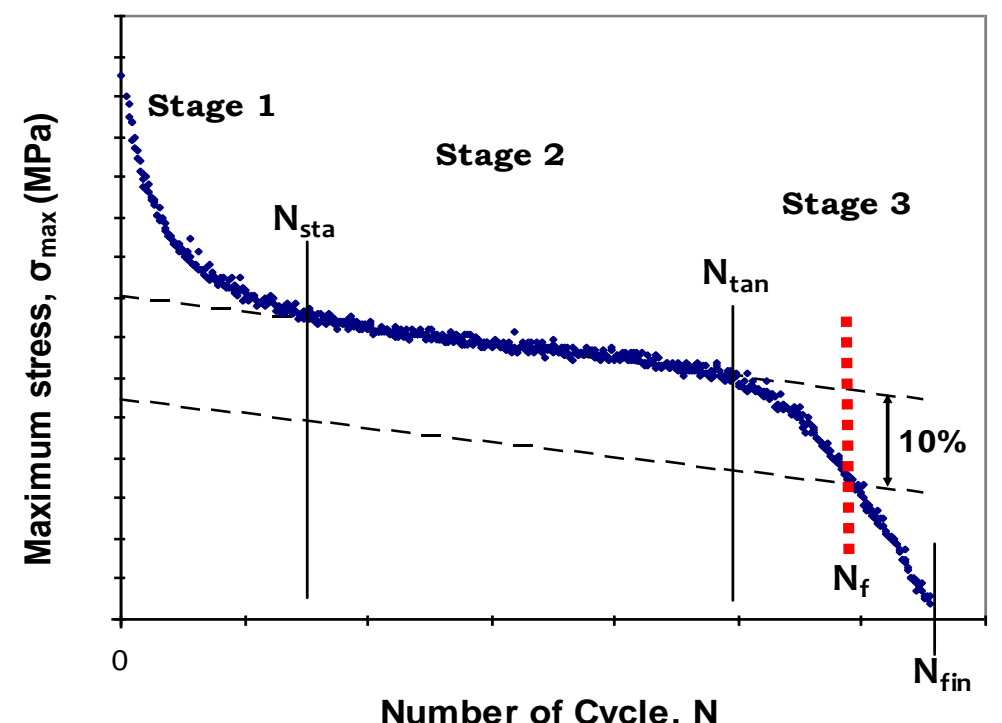

Figure 3. Definitions of $\mathrm{N}_{\text {sta }}, \mathrm{N}_{\mathrm{tan}}$ and $\mathrm{N}_{\mathrm{f}}$ obtained from a cyclically softened material. 
Figure 4(a) shows the variation of elastic modulus with load cycles in the straincontrolled tests of P91 steel with different strain amplitudes. It can be seen that the modulus values are practically constant for about the first $70 \%$ of the recorded hysteresis loops for each test. During the latter stages of life, the modulus values decrease significantly until the last recorded cycles. Major cracks can be clearly seen on the surfaces of these specimens. It is also observed that the hysteresis loop area values show stability during second stage of cyclic softening, as shown in Figure 4(b), and the values also decrease in the final stages of cyclic softening. The observations indicate damage evolution in the specimen [14] and that less energy is required to deform the material in this stage as compared to the previous two stages.

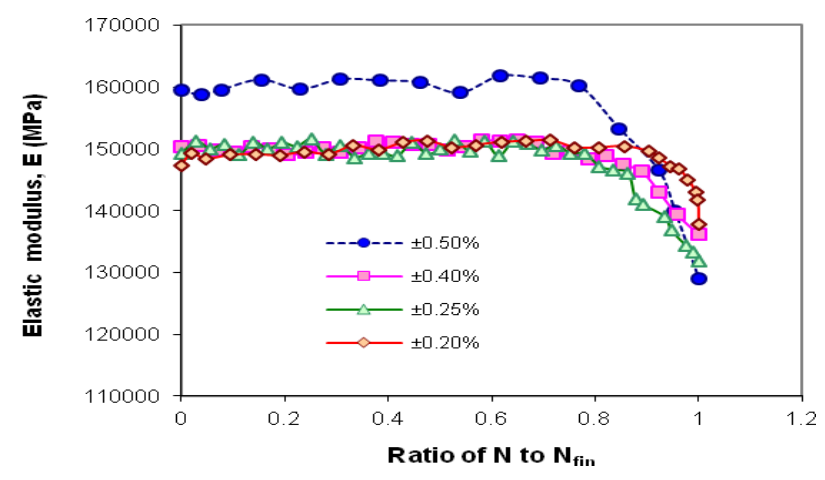

(a)

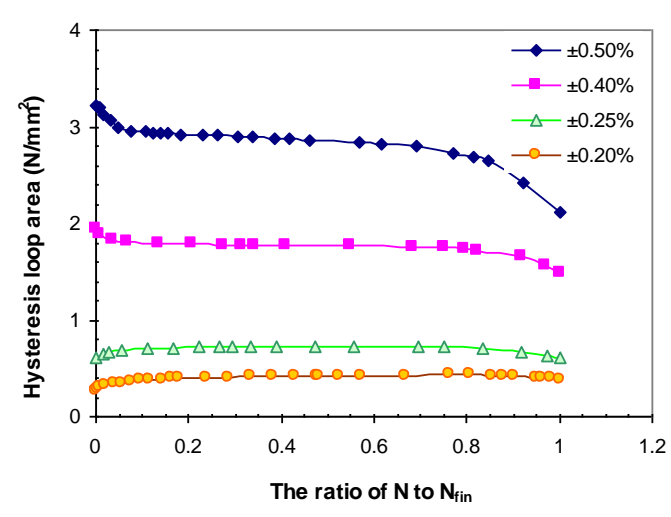

(b)

Figure 4. (a) Plot of elastic modulus versus the ratio of the cycle number to the final recorded cycles for tests with various strain amplitudes for P91 steel at $600{ }^{\circ} \mathrm{C}$. (b) The hysteresis loop area values show stability during the second stage of cyclic softening.

The evolution of elastic modulus can be used as an indication of the strength degradation of the material. Lemaitre and Chaboche [14] proposed that the damage, $D$, of a material may be given by the following equation:

$$
D=1-\frac{\tilde{E}}{E}
$$

where $E$ is the elastic modulus of the material free from damage, $\widetilde{E}$ is the elastic modulus of the damaged material and $0 \leq D \leq 1$. The damage parameter is equal to zero for the undamaged material and totally damaged material is represented by $D=1$.

Figure 5(a) shows a plot of damage versus cycle for the test with $\pm 0.5 \%$. The damage values are negligible for the majority of cycles from the beginning and start to increase from the 500th cycle to the last recorded cycle, i.e. the 655 th cycle, which gives a damage value of about 0.2 , leading to sudden fracture of the specimen, with no clear sign of specimen necking, at the end of the test. The stress-strain loop at the final number of recorded cycles, as shown in Figure 5(b), shows a "hysteresis loop tail" at the base of the compressive stress part of the loop, which indicates the occurrence of cracks [19]. The stress-strain loop of the undamaged material shows a similar trend of nonlinearity under tension and compression conditions. Figure 5(c) shows microcracks found at 400 cycles; the cracks propagate in the third stage of cyclic softening and become significant cracks that can be clearly observed on the specimen's surface, as shown in Figure 5(d). 

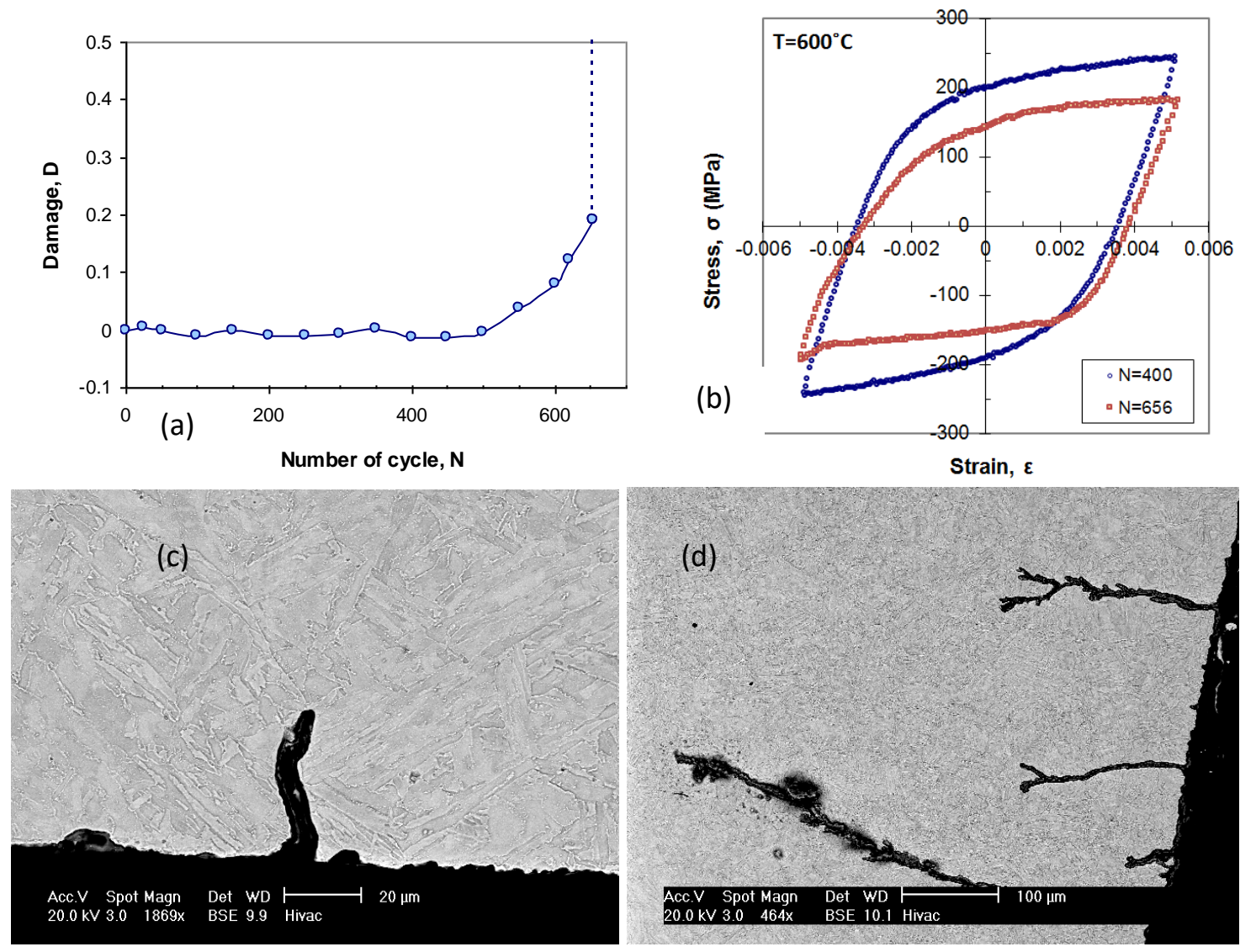

Figure 5. (a) The evolution of damage throughout the $\pm 0.5 \%$ strain-controlled test at $600{ }^{\circ} \mathrm{C}$. The stress-strain loop at the final number of recorded cycles (b) shows a "hysteresis loop tail" at the base of compressive stress part of the loop. SEM images of

(c) microcracks, found at 400 cycles, and (d) cracks at the end of the cyclic testing.

Figures 6(a) to (d) show the bright field TEM images for different life fractions, i.e., (a) as received material, (b) 200th cycle, (c) 400th cycle and (d) 656th cycle . By using the line intersection technique, the subgrain sizes for Figures 4(a) to (d) are 0.383, $0.507,0.551$ and $0.604 \mu \mathrm{m}$, respectively. It can be seen that the subgrains are coarsened as the number of cycles increase, particularly in the first stage of cyclic softening where the results show rapid subgrain coarsening during this stage without affecting the strength of the specimen, as indicated by the Young's modulus. This phenomenon is related to the rapid decrease of the maximum stresses during stage 1.

The subgrain coarsening is attributed to the annihilation of low angle boundaries, as explained by Sauzay, Brillet [20]. The authors reported that the misorientation angles between laths (or subgrains) are low (smaller than $5^{\circ}$ ) and that they can be modelled as dislocation arrays. During plastic deformation, mobile dislocations move towards low angle boundaries of opposite signs and the interactions between the opposite signs of dislocations cause the dislocations to be annihilated. As the cycle number continues to increase, the dislocations inside the subgrains decrease and finally contribute to the disappearance of the low angle boundaries. Consequently, the subgrain size coarsens and the density of the dislocations decreases, which means that there is a reduction of the number of obstacles to plastic deformation. Thus, lower stresses are required to achieve a certain deformation, as shown by the rapid decrease of the peak stress levels. 
During the third and final stage of cyclic softening there is a nonlinear decrease of the peak stress level that corresponds to the occurrence of damage. In this period, the subgrain size has slightly increased. However, it is clear that during this stage the microcracks, which were observed at the end of the second stage, continue to propagate. The SEM images of failed specimens show transgranular cracking with crack branching. Similar crack observations have been found by Nagesha, Valsan [12] for modified 9Cr1 Mo steel at the same temperature. As the size of the cracks becomes larger, they affect the Young's modulus value of the material, leading to a reduction of the modulus value. This can be attributed to the degradation of the strength of the material, as shown by the evolution of damage, D, in Figure 5(a). As the material becomes weaker, lower stresses are required to achieve the targeted strains in the cyclic testing specimens.
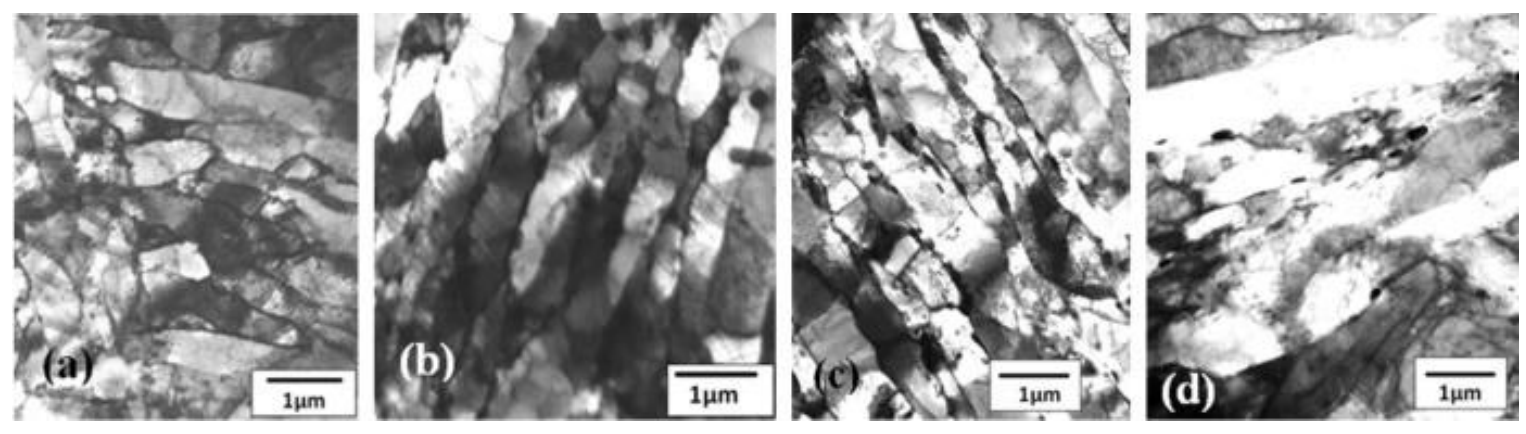

Figure 6. Bright field TEM images for (a) the as-received material, and the subgrain evolution that occurs in the $\pm 0.5 \%$ strain-controlled test at the (b) $200^{\text {th }}$, (c) $400^{\text {th }}$ and (d) $656^{\text {th }}$ cycle.

\section{CONCLUSIONS}

Cyclic loading applied on the P91 steel at high temperatures produces three distinct stages of cyclic softening, which corresponds to different levels of damage identified from the full cycle data of the P91 cyclic tests. The first stage of cyclic softening shows the nonlinear decrease of the peak stress level owing to a microstructure evolution as a result of subgrain coarsening. The cyclic mechanical parameters become stabilised in the second stage of cyclic softening. Furthermore, the initiation of cracks begins in this stage. The changes of structure, on a micro-scale, do not significantly affect the damage of the specimen in stages 1 and 2 as the Young's modulus values of the specimen remain approximately constant up to the end of stage 2 of cyclic softening. The nonlinear decrease of the peak stress level, which occurs in the third stage, is owing to crack propagation. The cracks cause the material to become weaker, as indicated by the increase of the damage, D, value. The results of cyclic loading experiments of the P91 steels at $600{ }^{\circ} \mathrm{C}$ with the microscopic investigation images can be referenced to other researchers interested in power plant materials, and similar works can be extended with another type of martensitic steel, such as P92 steel.

\section{ACKNOWLEDGEMENT}

The author would like to acknowledge the support of Universiti Sains Malaysia through USM's short term grant 304/PMEKANIK/60312038. 


\section{REFERENCES}

[1] Brett S. Service experience of weld cracking in CrMoV steam pipework systems. Second International Conference on Integrity of High Temperature Welds, London. 2003; 3-17.

[2] Li M, Barrett RA, Scully S, Harrison NM, Leen SB, O’Donoghue PE. Cyclic plasticity of welded P91 material for simple and complex power plant connections. International Journal of Fatigue. 2016;87:391-404.

[3] Hayhurst R, Mustata R, Hayhurst D. Creep constitutive equations for parent, Type IV, R-HAZ, CG-HAZ and weld material in the range 565-640 C for $\mathrm{Cr}-\mathrm{Mo}-\mathrm{V}$ weldments. International Journal of Pressure Vessels and Piping. 2005;82:137-44.

[4] Hyde T, Becker A, Sun W, Williams J. Finite-element creep damage analyses of P91 pipes. International Journal of Pressure Vessels and Piping. 2006;83:853-63.

[5] Hyde C, Sun W, Hyde T, Saad A. Thermo-mechanical fatigue testing and simulation using a viscoplasticity model for a P91 steel. Computational Materials Science. 2012;56:29-33.

[6] Nilsson K-F, Dolci F, Seldis T, Ripplinger S, Grah A, Simonovski I. Assessment of thermal fatigue life for $316 \mathrm{~L}$ and $\mathrm{P} 91$ pipe components at elevated temperatures. Engineering Fracture Mechanics. 2016;168:73-91.

[7] Li D-F, Barrett RA, O'Donoghue PE, Hyde CJ, O'Dowd NP, Leen SB. Micromechanical finite element modelling of thermo-mechanical fatigue for P91 steels. International Journal of Fatigue. 2016;87:192-202.

[8] Kamal M, Rahman M. Fatigue life estimation models: a state of the art. International Journal of Automotive and Mechanical Engineering. 2014;9:1599608.

[9] Kamal M, Rahman M. An Integrated Approach For Fatigue Life Estimation Based On Continuum Mechanics Theory And Genetic Algorithm. International Journal of Automotive and Mechanical Engineering. 2015;11:2756-70.

[10] Shukri M, Rahman M, Ramasamy D, Kadirgama K. Artificial neural network optimization modeling on engine performance of diesel engine using biodiesel fuel. International Journal of Automotive and Mechanical Engineering. 2015;11:2332-47.

[11] Bernhart G, Moulinier G, Brucelle O, Delagnes D. High temperature low cycle fatigue behaviour of a martensitic forging tool steel. International Journal of Fatigue. 1999;21:179-86.

[12] Nagesha A, Valsan M, Kannan R, Rao KBS, Mannan S. Influence of temperature on the low cycle fatigue behaviour of a modified $9 \mathrm{Cr}-1 \mathrm{Mo}$ ferritic steel. International Journal of Fatigue. 2002;24:1285-93.

[13] Fournier B, Sauzay M, Barcelo F, Rauch E, Renault A, Cozzika T, et al. Creepfatigue interactions in a 9 Pct Cr-1 Pct Mo martensitic steel: part II. microstructural evolutions. Metallurgical and Materials Transactions A. 2009;40:330-41.

[14] Lemaitre J, Chaboche J. Mechanics of solid materials Cambridge University Press Cambridge Google Scholar. 1990.

[15] Barrett RA, Farragher T, O’Dowd N, O’Donoghue P, Leen S. Multiaxial cyclic viscoplasticity model for high temperature fatigue of P91 steel. Materials Science and Technology. 2014;30:67-74. 
[16] Lu J, Sun W, Becker A, Saad AA. Simulation of the fatigue behaviour of a power plant steel with a damage variable. International Journal of Mechanical Sciences. 2015;100:145-57.

[17] Constantinescu A, Charkaluk E, Lederer G, Verger L. A computational approach to thermomechanical fatigue. International Journal of fatigue. 2004;26:805-18.

[18] Standard B. Constant amplitude strain controlled axial fatigue - BS7270:2006 Metallic Materials: Method of tTest; 2006.

[19] Dunne F, Makin J, Hayhurst D. Automated procedures for the determination of high temperature viscoplastic damage constitutive equations. Proceedings of the Royal Society of London A: Mathematical, Physical and Engineering Sciences: The Royal Society. 1992;527-44.

[20] Sauzay M, Brillet H, Monnet I, Mottot M, Barcelo F, Fournier B, et al. Cyclically induced softening due to low-angle boundary annihilation in a martensitic steel. Materials Science and Engineering: A. 2005;400:241-4. 